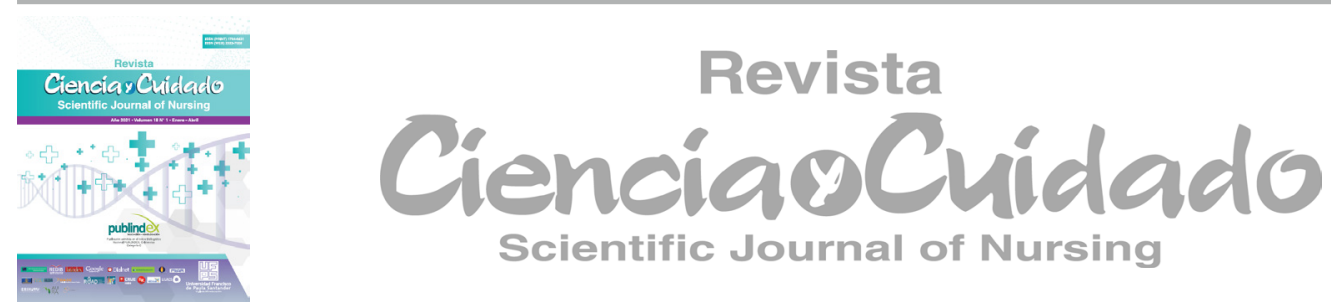

Articulo Original

\title{
Creencias frente al embarazo y enfermedades bucodentales percibidas por gestantes en Montería, Colombia.
}

\author{
Beliefs against pregnancy and oral diseases perceived by pregnant women in Mon- \\ tería, Colombia
}

\section{Crenças contra gravidez e doenças bucodentais percebidas por gestantes em Mon- teria, Colômbia}

\author{
Nydia Nina Valencia-Jiménez ${ }^{1}$ \\ Sarita Luz De Arco-Montiel ${ }^{2}$
}

\section{Resumen}

Objetivo: Interpretar las creencias de susceptibilidad percibida entre la condición de embarazo y las enfermedades bucodentales por mujeres gestantes de la ciudad de Montería, en el Departamento de Córdoba, Colombia. Materiales y métodos: Estudio cualitativo con enfoque microetnográfico, cuyos resultados se obtuvieron mediante la observación y las entrevistas a profundidad que fueron aplicadas a 19 gestantes adscritas a un hogar comunitario de la comuna cuatro de la ciudad de Montería, Córdoba, en 2019, quienes fueron seleccionadas por conveniencia. La información se recolectó durante el I semestre del 2019 y se organizó a partir de la dimensión del Modelo de creencias en salud: susceptibilidad percibida. El análisis se realizó bajo los parámetros de la técnica de análisis de contenido. Resultados: La creencia de susceptibilidad que predominó entre las gestantes fue que en el periodo de embarazo las enfermedades bucales son normales y que su origen obedecía a la succión del calcio a la madre por parte del bebé para su crecimiento. Conclusión: Las creencias que poseen las gestantes actúan como barreras frente a la adopción de comportamientos saludables y de su permanencia en programas de promoción de la salud oral y prevención de las enfermedades bucodentales.

Palabras claves: Mujeres embarazadas; susceptibilidad a enfermedades; medicina oral; cultura; antropología cultural.
Autor de correspondencia*

1* Desarrollista Familiar, Magíster en Educación. Docente catedrática de la Facultad de Ciencias de la Salud en la Universidad de Córdoba, Montería - Córdoba. Correo: nnvalencia@correo.unicordoba.edu.co iD

${ }^{2}$ Odontóloga, Magíster en Salud Pública. Odontóloga general en Centro Médico Integral del Corazón, Montería - Córdoba. Correo: saritadearco04@gmail.com (iD

Recibido: 23 abril 2020

Aprobado: 20 octubre 2020

Para citar este articulo:

alencia-Jimenez NN, De Arco-Montien SL. Creencias frente al embarazo y enfermedades bucodentales percibidas por gestantes en Montería, Colombia. Rev. cienc. cuidad. 2021;18(1):20-29. https://doi. org/10.22463/17949831.2320

(C) Esta obra está bajo licencia internacional CC-BY-NC-ND (c) (1) (3) 


\begin{abstract}
Objective: To interpret the beliefs of perceived susceptibility between the condition of pregnancy and oral diseases by pregnant women in Monteria, Córdoba, Colombia. Material and method: Qualitative study with a micro-ethnographic approach. The results were gotten through observation and in-depth interviews that were applied to 19 pregnant women of the commune four in Monteria, Córdoba in 2019, selected by convenience. The information was collected during the first semester of 2019, and it was organized based on the dimension of the Health Belief Model: perceived susceptibility; the analysis was performed under the parameters of the content analysis technique. Results: the prevailing belief among pregnant women was that oral diseases were caused because the baby got all the calcium during pregnancy. Conclusion: The threats suffered by pregnant women act as barriers against the adoption of healthy behaviors, and their permanence in programs to promote oral health and prevent oral diseases.
\end{abstract}

Keywords: pregnant women, disease susceptibility, oral medicine, culture.

\title{
Resumo
}

Objetivo: Interpretar as crenças de susceptibilidade percebida durante a gravidez das doenças bucais e dentais por gestantes na cidade de Monteria, no estado de Córdoba, Colômbia Materiais e métodos: Estudo qualitativo com foco micro etnográfico, os resultados obtiveram-se mediante observação e as entrevistas a profundidade aplicadas em 19 mulheres grávidas de um lar comunitário da comuna quatro da cidade de Monteria, Córdoba em 2019. Organizou-se a partir da dimensão do modelo de crenças em saúde: susceptibilidade percebida. A análise realizou-se seguindo os parâmetros da técnica de análise de conteúdo. Resultados: A crença de susceptibilidade que se observou durante a gravidez perante as doenças dentais e bucais são normais e que a sua origem obedeceu à sucção do cálcio da mãe para o neném em formação. Conclusão: As crenças que possuem as grávidas atuam como empecilhos frente a adoção de comportamentos saudáveis e de permanência em programas de promoção da saúde oral e das doenças bucais e dentais.

Palavras-chave: gestantes, susceptibilidade a doenças, medicina bucal, cultura, antropologia cultural.

\section{Introducción}

La relación entre salud bucal y salud general es más estrecha de lo que muchos creen. Existen factores de riesgo comunes que han sido documentados y que ponen de manifiesto la necesidad de trabajar con mayor ahínco en las políticas de salud bucal en el mundo. En este contexto, se referenciarán los datos que se consideran de mayor interés para este estudio (sin que con esto se complete el universo de conexiones que pudiesen existir entre estas). En el caso específico de la periodontitis severa, hay evidencias que muestran como esta enfermedad afecta de forma negativa el control glucémico en la diabetes y la glucemia en los sujetos sin diabetes (1). por otro lado, cuando la periodontitis no se trata adecua- damente se podría relacionar con trastornos del embarazo referidos a preclamsia, bajo peso al nacer y partos prematuros (2-4); además de otras investigaciones que muestran cómo la caries dental puede transmitirse de forma vertical de la madre al hijo (2).

En Colombia, el IV Estudio Nacional de Salud Bucal evidenció que $89 \%$ de la población de mujeres en periodo de gestación padece alguna enfermedad bucal, porcentaje de interés por ser este un grupo considerado vulnerable en Colombia, particularmente en el Departamento de Córdoba, que se encuentra entre las regiones colombianas con mayores índices de necesidades básicas insatisfechas $(59,09 \%)$, analfabetismo $(37,60$ $\%$ ) y desempleo $(9,1 \%)$, entre otros determinantes que afectan la salud de las gestantes (5); pero que también 
podrían facilitar la aparición de enfermedades bucales relacionadas con la desatención de factores biopsicosociales durante el embarazo (2).

Hay que precisar que las mujeres en gestación de este Departamento se encuentran en riesgo latente al desarrollar su embarazo en una región que durante los últimos 12 años mantiene una razón de mortalidad materna que supera la media nacional, cuya variación se da entre 69,5 y 197 casos por 100.000 nacidos vivos. Lo anterior, podría obedecer a los determinantes sociales de la zona $(6,7)$, particularmente a las barreras de acceso en los servicios de salud, deficiencias en los programas de promoción y mantenimiento de la salud, entre otros.

De acuerdo con estas consideraciones, surgen interrogantes acerca del por qué los programas y proyectos que van destinados a las gestantes muestran limitaciones y poca efectividad, aun cuando se ha constatado que son necesarios para el bienestar de la mujer en gestación. Todo esto, conduce a centrar la atención en las creencias que construye la población frente a la salud, porque allí es donde se podrían ver reflejados los temores o tabúes que existen acerca de las enfermedades, particularmente las bucales y sus posibles tratamientos $(8,9)$.

Es conveniente destacar que las creencias o valoraciones internas se trasmiten por personas que tienen cierta confiabilidad para el individuo (familia, sociedad, etnia) o se obtienen mediante vivencias o experiencias y en gran medida son determinantes en el comportamiento que se tome referente a la salud (10). Dentro de los modelos teóricos que existen para el abordaje de las creencias en salud se destaca el creado por Hochbaum, Rosenstock, Becker y otros autores quienes proponen entre sus tesis que la conservación, mejoramiento de la salud y adopción de estilos de vida saludables van a depender de cuatro dimensiones: la susceptibilidad percibida ante un determinado problema de salud y la percepción subjetiva del riesgo de enfermar; la severidad percibida, las creencias sobre la gravedad de contraer una enfermedad determinada y en el caso de enfermar, las implicaciones de no tratarla; los factores modificantes, que son aquellos factores internos o externos que determinan la realización de comportamientos en salud; los beneficios percibidos que se obtienen al llevar a cabo determinada acción; $y$, por último, las barreras, bien sean físicas o mentales que no dejan realizar o adoptar comportamientos preventivos en salud $(11,12)$.

En el presente artículo se abordará la dimensión de susceptibilidad percibida, bajo el Modelo de Creencias en
Salud-MCS, la cual refleja el sentir del individuo con relación a la vulnerabilidad propia frente a un problema específico en salud (en este caso salud oral); es decir, se abordará cómo varía la percepción de vulnerabilidad de cada individuo en lo que concierne a una determinada condición de salud bucal, pasando por las percepciones propias de: "niego cualquier posibilidad de enfermarme", "puede que me enferme" y la aceptación propia de que "estoy en riesgo de enfermarme" (12). Por ello, el objetivo de la presente investigación es interpretar las creencias de susceptibilidad en la salud bucal de mujeres gestantes, mediante el MCS que hace parte de las teorías cognitivo sociales y buscan dar explicación a los comportamientos en salud por parte de los individuos.

Por tanto, esta investigación permitirá conocer desde el punto de vista de las gestantes la postura que estas asumen frente a la aparición de enfermedades bucales y se espera que aporte elementos para comprender el por qué los programas de prevención de las enfermedades, así como la promoción de la salud que se lleva a cabo en este grupo poblacional no logran disminuir significativamente los índices de las enfermedades bucodentales.

\section{Objetivo}

Interpretar las creencias de susceptibilidad percibida entre la condición de embarazo y las enfermedades bucodentales por mujeres gestantes de la ciudad de Montería en el Departamento de Córdoba, Colombia

\section{Materiales y Métodos}

Investigación cualitativa de tipo microetnográfica que permite conocer y entender el comportamiento en una determinada comunidad y cómo los individuos valoran y conceden importancia a las situaciones cotidianas. Este tipo de investigación se considera como una rama de la antropología, por cuanto se dedica a la observación y descripción de diferentes aspectos de una cultura, comunidad o pueblo como: el idioma, costumbres, creencias y los estilos de vida en tiempos prolongados. También busca registrar lo vivido por los otros en el marco de sus interacciones micro sociales que faciliten la comprensión desde la diversidad de estructuras, creencias y pensamientos (13).

Se escogieron 19 gestantes por conveniencia con una edad mínima de 18 años y máxima de 33 años, quienes cumplían con los siguientes criterios de inclusión: mu- 
jeres gestantes que se encuentren en el primer, segundo y tercer trimestre del embarazo; gestantes que hayan firmado el consentimiento informado, y que por tanto, aceptaron participar en el estudio de forma voluntaria; gestantes que asisten a un hogar comunitario ubicado en un barrio de la comuna cuatro, de la ciudad de Montería, Córdoba. Asimismo, se tuvieron en cuenta los siguientes criterios de exclusión: gestantes que no hayan accedido a firmar el consentimiento informado; gestantes que presenten alguna patología psíquica importante que les dificulte la realización de la entrevista; gestantes con problemas para comunicarse que les impida realizar las entrevistas.

Los instrumentos empleados para la recolección de datos fueron: la observación, diario de campo y entrevista a profundidad, dividida en dos secciones: datos sociodemográficos (edad, nivel educativo, etnia, ocupación, nivel de ingresos) y con las siguientes preguntas guía: (i) qué piensa usted acerca de las enfermedades bucodentales; ii) cree usted que una gestante deba visitar al odontólogo; iii) considera que las enfermedades bucodentales podrían afectar al bebé, entre otras.

El registro de la información fue grabado y transcrito, previoconsentimiento de las participantes. El instrumento se sometió a la evaluación de expertos, aplicándose en un primer momento a un grupo de gestantes para verificar la comprensión de las preguntas. Posteriormente el instrumento se ajustó y fue aplicado a las participantes seleccionadas en este estudio, en sus hogares, con una duración aproximada de 60 minutos. E1 número de participantes se obtuvo a partir de la técnica de saturación teórica, que consistió en que al momento en que la información recolectada se hacía repetitiva (punto de saturación) se finalizó con las entrevistas y se realizó la interpretación de los resultados.

Los datos se analizaron utilizando la técnica de análisis de contenido que según los criterios de Bardin, consiste en ordenar la información, categorizarla y definir la unidad de análisis del texto. La técnica de análisis de contenido se llevó a cabo en tres fases:

Fase I: Pre-análisis. En esta primera etapa se organizó y preparó el material que se iba a analizar, catalogado por Bardin como el establecimiento del corpus, por lo que se tomaron en cuenta cuatro criterios: exhaustividad, representatividad, homogeneidad y pertinencia (14).

Fase II: Exploración de material. En esta fase los datos obtenidos se transformaron, organizaron y catego- rizaron manualmente.

Fase III. Resultados, inferencia e interpretación. Se realizó una lectura detallada de cada una de las entrevistas, leyendo dos o tres veces según fuese necesario; a continuación se resaltaron con distintos colores los aspectos significativos narrados por las gestantes en función de la dimensión del MCS. Posteriormente se hizo una matriz de codificación en la cual se ubicaron frases o palabras significativas identificadas en la transcripción de las entrevistas (descriptores). En la siguiente columna, a la derecha, se identificaron las subcategorías y categorías que se resaltaron del análisis del texto, buscando sintetizar la respuesta pero que no perdiese su esencia.

La investigación se acogió a la Resolución No. 008430 de 1993 - Artículo 11 del Ministerio de Salud y Protección Social de Colombia, el cual la cataloga como una investigación de riesgo mínimo; la información se codificó con el fin de proteger la confidencialidad de las gestantes, mediante el empleo de códigos alfanuméricos para garantizar el anonimato. Para el control de sesgos se verificó que las gestantes estuviesen afiliadas al hogar comunitario contexto de la investigación, que estuvieran radicadas en la ciudad de Montería y que se encontraran en estado de embarazo. La investigación fue aprobada por el Comité de Ética de la Facultad de Ciencias de la Salud de la Universidad de Córdoba.

\section{Resultados}

Las participantes son mujeres con edades comprendidas entre los 18 y 33 años, en su mayoría viven en unión libre, son amas de casa, viven en el estrato 1, tienen la primaria completa y secundaria incompleta y están en el tercer semestre del embarazo.

En la dimensión de susceptibilidad que integra el Modelo de Creencias en la Salud-MCS- se identificó la categoría: "lidiando con enfermedades nuevas en mi", de la cual hacen parte las subcategorías "aparición de enfermedades bucales gracias al embarazo" e "higiene bucal, ¿la solución?", con las que se busca englobar las percepciones referidas por las gestantes en relación con la aparición de enfermedades bucales nuevas para ellas.

Los resultados permiten evidenciar -desde el imaginario de las gestantes- la relación que para ellas tiene el embarazo con la aparición de caries o de los dolores 
dentales:

- "Cuando mi primer embarazo me dio un dolor en las muelas y me daba mucha sensibilidad cuando comía, por ejemplo, algún dulce o algo así me dolía la muela, eso fue durante el embarazo, cuando di a luz más nunca me ha dado la sensibilidad, ni el dolor" (G15).

- "Se me dañaron todos los dientes, supuestamente el doctor dice que hice la barriga fue en los dientes, que hay algunas mamás que les pasa eso" (G12).

Las respuestas de las gestantes muestran que para ellas el embarazo es una causal directa e íntima para la aparición de caries (condición que más asocian con enfermedad bucal) y sensibilidad dental; esta creencia se viene consolidando por todo el mundo, e inclusive se relaciona el embarazo con la pérdida de órganos dentales. Las participantes referían que esta "reciente" aparición de enfermedades bucales, se debía a la pérdida de calcio que sufrían gracias al bebé; es decir, que desde su perspectiva, el feto les succiona el calcio de los dientes volviéndolas vulnerables a las enfermedades bucales:

- "Los niños le roban el calcio a uno, y mira que yo siento que sí, porque yo tomo vitaminas y siento que me estoy enflaqueciendo más, todo lo jala él" (G16).

- "Yo cuando estaba embarazada de la niña me empezó un huequito ahí, una caries, como que me estaba chupando el calcio, y eso fue lo que me pasó, me estaba chupando el calcio, siempre pasa así, porque tengo varias amigas que han salido en embarazo y siempre el calcio se lo chupan" (G7).

- "El bebé descalcifica, el embarazo lo descalcifica a uno, el bebé le está cogiendo el calcio a uno de los huesos y como los dientes son hueso" (G13).

- "Cada embarazo es una fuente de calcio que nosotros perdemos, tanto en los huesos de acá de nuestras piernas, ahora imagínense de las muelas que son algo que también son hueso, entonces se dañan las muelas" (G3).

A partir de estas observaciones inéditas, se puede inferir que las gestantes tienen la creencia de que la aparición de enfermedades bucales está asociada a la falta de calcio que el bebé les "roba" para su formación; es decir, las mujeres construyen su imaginario a partir de establecer que son ellas la principal fuente de alimentación y desarrollo del feto, razones que podrían justificar el por qué creen que el calcio que los niños necesitan para los huesos lo toman también de ellas, de sus huesos y de sus dien tes.

Por otra parte, las gestantes consideraron como una vulnerabilidad ante la aparición de enfermedades bucales el sexo del bebé, este supuesto se estableció a partir de sus observaciones:

- "Tengo varias amigas que han salido en embarazo y siempre el calcio se lo chupan... más que todos los varones, la mía fue hembra y me chupó el calcio de la muela, dicen que el varón es el más fuerte, por eso jala más calcio y parte más la muela" (G7).

Al mismo tiempo, otra creencia que tienen las gestantes se asocia con el mes de gestación en que se encuentren, e incluso al tamaño de su barriga:

- "Eso va por tiempo, por temporada, como no puedes tener, si puedes tener, depende del mes de gestación, el mes de gestación ahí se le va viendo todo lo que tú comes, que no comes" (G20).

- "Cuando la barriga me empezó a crecer, eso como que me crecía más, se me puso el huequito más grande, se me fue poniendo como un huequito y se me comió" (G7).

También, la investigación reflejó que existen creencias respecto a la salud oral por parte de las gestantes con cierto aire místico; las mismas incluyen al padre quien también puede sufrir enfermedades bucales, tal y como lo mencionan en sus observaciones:

- "El dolor de muelas lo tuvo fue él (esposo), eso sí duele, a él el dolor no lo dejaba ni comer, eso era el embarazo, ajá hay una conexión, ¡como es el hijo!, cuando yo quedé embarazada a él le dolió la muela inmediatamente, al pasar de los meses se le quitó" (G19).

No obstante, algunas participantes expresan que la susceptibilidad a contraer enfermedades bucales, no es solo por el hecho de estar embarazadas, sino que también lo asocian con la mala higiene bucal:

- "Si uno no se asea bien su dentadura, puede haber una enfermedad o una bacteria, entonces yo diría que de pronto es lo mismo" (G1).

- "Yo creo que todo el mundo está expuesto a obtener cualquier enfermedad sea de la boca, sin importar si está uno embarazada o no" (G4).

Es decir, que para este grupo de gestantes no hay aso- 
ciación alguna entre el embarazo y la aparición de enfermedades bucales, y que estas últimas son el resultado de una deficiente higiene bucal, creencia que podría estar vinculada a una correcta educación en salud oral.

\section{Discusión}

El éxito de los programas de promoción de la salud oral y prevención de las enfermedades bucales contempla un conjunto de factores, uno de estos es lograr que los beneficiarios de dichos programas transformen sus comportamientos, lo cual desde la perspectiva de Rosenstock y su MCS solo es posible cuando se comprenden las causas que los originan. Las bases de este Modelo señalan como factor importante la interacción del sujeto con el entorno sociocultural como una realidad indisoluble, en donde las creencias actúan como filtros ante las formas de percibir el mundo; además, junto a los valores se constituyen en la principal motivación para la conservación o suspensión de un determinado comportamiento saludable frente a quienes ponen en riesgo la salud humana $(12,15)$.

El foco de atención del presente estudio, lo constituyen las creencias sobre la susceptibilidad que perciben las participantes con relación al embarazo y las enfermedades bucodentales, cuyo hallazgo central da cuenta que las gestantes creen que estar embarazadas las hace susceptibles a padecer enfermedades bucodentales; además consideran que la principal causa de estas enfermedades obedece a la pérdida de calcio como fruto del proceso de formación óseo de sus hijos. Estos constructos sociales son percibidos por las mujeres gestantes de otras regiones colombianas (8) y latinoamericanas (16-19) trasmitiéndose de generación en generación, dando explicaciones que son creíbles para ellas.

El calcio es un mineral indispensable para el fortalecimiento de los huesos, la mayoría del calcio se almacena en los huesos y en los dientes, por consiguiente este mineral debe ser aportado por la madre al feto, pero se debe anotar, que el calcio se obtiene de los alimentos y de la dieta materna $(20,21)$.

También se debe precisar que el embarazo genera cambios físicos externos e internos en el organismo de la mujer, en parte, por el aumento hormonal que experimenta, el cual ocasiona alteraciones en la regulación salival de la cavidad bucal y la vuelve más susceptible a la aparición de enfermedades bucales. No obstante, susceptibilidad no significa veracidad o afirmación, porque la evidencia señala que el esmalte dental está compuesto por cristales de hidroxiapatita, lo que no significa que sufran alguna alteración por el embarazo; por tanto, se podría decir que si la gestante tiene adecuadas prácticas en salud oral evitaría la aparición de dichas enfermedades bucales $(2,8,22)$.

Por otra parte, la saliva cumple funciones de protección, limpieza y lubricación, además desempeña un efecto antimicrobiano en las superficies y mucosas dentales. En la gestación la composición salival se altera, por lo que el $\mathrm{pH}$ y la capacidad reguladora de la saliva disminuyen, convirtiendo la cavidad bucal de la gestante en un sitio favorable para el desarrollo y crecimiento bacteriano. Sin embargo, se deben considerar otros factores para el desarrollo de caries dental en la gestante, como lo son el aumento de la ingesta alimentaria y los cambios en la dieta (debido a un mayor requerimiento energético en el cuerpo de la gestante), al igual que el aumento de la cantidad de bacterias y acidez salival (8, 23-25). A los componentes anteriores se debe sumar la inadecuada higiene bucal; por tanto, la relación del embarazo con las enfermedades bucales que algunas gestantes establecen se debe al intercambio de saberes con personas que ejercen en cierta manera una autoridad hacia ellas, así como por la falta de información sobre el tema y las falencias de los programas de educación en salud oral de la zona $(26,27)$.

Es importante tener en cuenta el estrato socioeconómico de las participantes, porque a partir de este se determinan las prioridades y necesidades de cada individuo. En este sentido el $100 \%$ de las gestantes viven en el estrato 1, y por lo general, su sustento económico está orientado a satisfacer necesidades primarias como el alimento o los servicios; de ahí, que la seda dental o el enjuague bucal ocupen un lugar secundario, más cuando su costo es elevado, factores que dificultan una prevención adecuada de la salud bucal por parte de este grupo poblacional. Por eso creen que solamente con el cepillado basta y que las enfermedades durante el periodo de gestación son "normales".

Del mismo modo, existe una asociación de las enfermedades bucales con el mes de gestación por parte de las participantes, buscando -a partir de su conocimiento empírico- respuestas al porqué de la aparición de estas enfermedades que son "nuevas" para ellas. Como se pudo comprobar, las gestantes expresaron que antes del embarazo no las tuvieron, o puede que sí, pero no eran lo suficientemente graves como para darse cuenta; no obstante, al pasar el tiempo y por el cambio hormo- 
nal del embarazo que vuelve más susceptible la cavidad bucal a la colonización bacteriana, permitiría acelerar la gravedad de las enfermedades bucales, siendo más notorias.

Otro aspecto de interés lo constituyen el conjunto de creencias que sugieren la relación entre el sexo del bebé y el riesgo de perder calcio, al otorgar primacía al sexo masculino; igualmente, se considera que en la medida que avanza el embarazo la susceptibilidad de contraer una enfermedad bucodental crece. También se asocia que la salud bucal del padre se ve afectada cuando su compañera sale en embarazo. La revisión de la literatura muestra que históricamente las comunidades tejen saberes frente al cuidado del embarazo $(28,29)$; asimismo, aprenden a identificar el sexo del bebé por la forma que adopta la barriga (30). Además, tratan de explicar los procesos, cambios físicos y emocionales que los padres pueden experimentar en el momento en que su pareja se encuentra en embarazo (31); sin embargo, no se tuvo acceso a registros sobre comunidades que establecieran las conexiones halladas en este estudio, lo que abre un camino de investigación sobre esta temática para identificar las bases que sustentan estas creencias.

Tampoco se debe pasar por alto, el hecho de que algunas gestantes manifestaron que ciertas creencias en salud bucal eran reafirmadas o generadas por el personal de salud. Por tanto, se puede inferir la existencia de brechas sobre los conocimientos que tienen los profesionales de la salud sobre la salud bucal en las gestantes; es decir, que esta actitud se deba al déficit de conocimientos en su formación profesional, no permitiéndoles disipar mitos y creencias erróneos con respecto a la salud bucal de sus pacientes y así orientarlas de manera adecuada. Ante esta situación, es necesario recalcar sobre la importancia de fomentar el conocimiento acerca del tema, mediante procesos de transdisciplinariedad en la atención de las gestantes $(32,33)$.

En definitiva, es imprescindible el trabajo y comunicación en equipo, por parte de todos los profesionales de la salud que hacen parte de los servicios de control prenatal y que de una $u$ otra forma tienen contacto con la gestante, puesto que ellos, en conjunto, son quienes representan un papel fundamental en el desarrollo integral del binomio madre-hijo (33).

\section{Conclusiones}

- Las gestantes muestran un comportamiento poco saludable frente a la salud bucal, puesto que lo asocian con las creencias que poseen frente a la relación embarazo y enfermedad bucodental; por tanto esta situación las aleja de los programas de promoción de la salud y prevención de las enfermedades, al no considerar de interés el control odontológico y suponer que todos los cambios relacionados con su cavidad bucal son normales.

- La educación en salud oral no debe ser vertical e impositiva, o que genere sentimientos de culpabilidad en la gestante sobre lo que ella conoce o cree. Es conveniente recordar que cada persona se encuentra ligada a un contexto sociocultural que promueve determinadas creencias, las cuales emergen cuando son requeridas; por tanto son formas como cada individuo ve y acepta el mundo, pues las creencias son parte de su realidad. Desde esta perspectiva se debe enseñar, eliminando aquellos constructos sociales que no favorecen la salud de la gestante y afianzando los que podrían favorecer la adopción de comportamientos saludables.

- Finalmente, no se debe dar por establecido que las creencias son parte exclusiva de las comunidades rurales o minorías étnicas; también hacen parte del imaginario social urbano, donde pese al contacto visible que se tiene con el sistema educativo, aún están presentes en los individuos. Cabe destacar que existen evidencias sobre la aparición de nuevas creencias que intentan explicar lo que se desconoce, como es el caso específico del sexo del bebé, la aparición progresiva de las enfermedades bucodentales en el proceso de gestación, o la presencia de afecciones bucales en los padres. Frente a todas las investigaciones y avances de la ciencia, solo queda la formación y trabajo inter y transdisciplinar para obtener mejores resultados en el cuidado prenatal.

\section{Conflicto de intereses}

No existe conflicto de intereses entre los autores. 


\section{Referencias Bibliográficas}

1. Chapple IL, Genco R. Diabetes and periodontal diseases: consensus report of the Joint EFP/AAP Workshop on Periodontitis and Systemic Diseases. Journal of Periodontology. [Internet]. 2013 [citado 2020 Ene 28]; 84(4):106-112. Disponible en: https://www.ncbi.nlm.nih.gov/pubmed/23631572

2. Díaz Valdés L, Valle Lizama RL. Influencia de la salud bucal durante el embarazo en la salud del futuro bebé. Gac Méd Espirit [Internet]. 2015 [citado 2020 Ene 28]; 17(1): 111-125. Disponible en: http://scielo. sld.cu/scielo.php?script $=$ sci arttext\&pid $=$ S1608-89212015000100012\&lng=es

3. Da Silva G, Coutinho S, Piscoya MD, Ximenes R. y Jamelli S. Periodontitis as a Risk Factor for Preeclampsia. Journal of Periodontology. [Internet]. 2012 [citado 2020 Ene 28]; 83(11), 1388-1396. Disponible en: https://www.ncbi.nlm.nih.gov/pubmed/22309175

4. Silk H, Douglass AB, Douglass JM, Silk L. Oral Health During Pregnancy. Am Fam Physician [Internet]. 2008; 77(9):1129-44. Disponible en: https://www.aafp.org/afp/2008/0415/p1139.html

5. Ministerio de Salud y Protección Social. Análisis de situación de salud (ASIS) Colombia 2018. Dirección de Epidemiología y Demografía. [Internet]. 2019 [citado 2020 Ene 28]. Disponible en: https://www.minsalud.gov.co/sites/rid/Lists/BibliotecaDigital/RIDE/VS/ED/PSP/asis-colombia-2018.pdf

6. Urzola-Vertel KC. Madres ausentes: Análisis de las muertes maternas en el Departamento de Córdoba 2016-2018 [tesis de maestría]. Córdoba: Universidad de Córdoba; 2019. 157 p.

7. Stanford-Arango MP. Relación entre los determinantes que inciden en la mortalidad materna del Departamento de Córdoba en los años 2008-2011 [tesis de maestría]. Perú: Universidad Peruana Unión; 2017. $127 \mathrm{p}$.

8. Alfaro-Alfaro A, Castejon-Navas I, Magán-Sánchez R, Alfaro-Alfaro M. Embarazo y salud oral. Rev clín med fam 2018; 11(3): 144-153. Disponible en: http://scielo.isciii.es/pdf/albacete/v11n3/1699-695X-albacete-11-03-00144.pdf

9. Ruiz-Chamorro T, Tomás-Sabado J. Impacto psicológico en la mujer durante el embarazo, parto y puerperio. Escuela Universitaria de Enfermería Gimbernat. [Tesis de grado]. 2017. 10-14 p. Disponible en: http:// eugdspace.eug.es/xmlui/bitstream/handle/123456789/470/Impacto $\% 20$ psicol\%c3\%b3gico $\% 20$ en $\% 20$ la $\% 20$ mujer $\% 20$ durante $\% 20 \mathrm{el} \% 20 \mathrm{embarazo} \% 2 \mathrm{c} \% 20$ parto $\% 20 \mathrm{y} \% 20$ puerperio.pdf?sequence $=1 \&$ isAllowed $=\mathrm{y}$

10. Moreno-San-Pedro E, Gil-Roales J. El modelo creencias de salud: revisión teórica, consideración crítica y propuesta alternativa. Hacia un Análisis Funcional de las Creencias en Salud. Int J Psychol Psychol Ther [Internet].2003;3(1):91-109. Disponible en: https://www.ijpsy.com/volumen3/num1/59/el-modelode-creencias-de-salud-revisi-ES.pdf

11. Díez A. Más sobre la interpretación (II). Ideas y creencias. Rev Asoc Esp Neuropsiq [Internet]. 2017;37(131):127-43. Disponible en: http://scielo.isciii.es/pdf/neuropsiq/v37n131/08.pdf

12. Abraham C, Sheeran P. The Health Belief Model. Research Gate [Internet] 2015; chapter 2: 31 - 36. Disponible en: https://www.researchgate.net/publication/290193215 The Health_Belief_Model

13. Murillo J, Martínez C. Investigación Etnográfica. Documento interno de trabajo Universidad Autónoma de Madrid. Recuperado de https://scholar.google.com/scholar_lookup?title=+La+investigaci\%C3\%B$\underline{3 \mathrm{n}+\mathrm{etnogr} \% \mathrm{C} 3 \% \text { A1 fica\&author }=\text { Murillo }+\mathrm{J} \& \text { publication_year }=2010}$

14. Díaz-Herrera C. Investigación cualitativa y análisis de contenido temático. Orientación intelectual de revista Universum. Rev. gen. inf. Doc [Internet]. 28(1) 2018: 125-130. Disponible en: https://www.researchgate.net/publication/326380221_Investigacion_cualitativa_y_analisis_de_contenido_tematico_Orien- 
tacion_intelectual_de revista_Universum

15. Arandes-Tinto JA. El análisis de contenido como herramienta de utilidad para la realización de una investigación descriptiva. Un ejemplo de aplicación práctica utilizado para conocer las investigaciones realizadas sobre la imagen de marca de España y el efecto país de origen. Provincia. [Internet]. 2013 [citado 2020 Ene 28]; 29(1):135-173. Disponible en: https:/www.redalyc.org/pdf/555/55530465007.pdf

16. Asmat-Abanto AS, Alvarado-Santillán GH. Creencias Populares sobre La Salud Oral de Embarazadas Atendidas en Dos Hospitales Peruanos. Int J Odontostomat [Internet]. 2019;13(4):486-92. Disponible en: https://scielo.conicyt.cl/pdf/ijodontos/v13n4/0718-381X-ijodontos-13-04- 00486.pdf

17. Carvajal-Pavez CE. Percepciones sobre la educación para la salud bucal, de mujeres que reciben atención odontológica integral para embarazadas RM 2014-2014_[tesis de maestría]. Santiago: Universidad de Chile; 2016.96 p.

18. Arias-Altamirano CA, Orozco F. Conocimientos, Actitudes y Prácticas de embarazadas en control prenatal relacionadas con salud oral y embarazo, de mujeres que acuden a consulta externa del Hospital Gíneco Obstétrico Isidro Ayora. Odontoinvestigación. 2017;3(1). https://doi.org/10.18272/oi.v3i1.850

19. Veliz-Vaca V. Factores que influyen en la inasistencia de las mujeres embarazadas a la atención odontológica durante los controles prenatales en seis centros de salud de primer nivel en Cercado, Cochabamba, Bolivia. Gac Med Bol. . [Internet]. 2018; 41(1):20-23. Disponible en: http://www.scielo.org.bo/pdf/gmb/ v41n1/v41n1a5.pdf

20. Bartrina JA. Calcio y vitamina D en el embarazo y la lactancia [Internet]. 2012. 17 p. Disponible en: $\underline{\text { ht- }}$ tps://www.nutricioncomunitaria.org/es/noticia-documento/25

21. Health NI of. Datos sobre el calcio [Internet]. 2016. p. 1-4. Disponible en: https://ods.od.nih.gov/pdf/ factsheets/Calcium-DatosEnEspanol.pdf

22. Anyosa-Calderón Y, Fernández-Quijandría B, Gamez-Cabanillas M, Hashimoto-Vargas P, Jiménez-Guillén A, Jiménez-Guillén A, et al. Mitos y evidencia en odontología sobre la gestación. Rev. Cient Odontol (Lima). 2019; 7 (1): 113-120.

23. Espinoza-E, Pachas F. Programas preventivos promocionales de salud bucal en el Perú. Rev Estomatol Hered [Internet]. 2013; 23(2):101-8. Disponible en: http://www.upch.edu.pe/vrinve/dugic/revistas/index. $\mathrm{php/REH/article/view/37/29}$

24. Alfaro-Alfaro A, Castejon-Navas I, Magán-Sánchez R, Alfaro-Alfaro M. Embarazo y salud oral. Rev clín med fam 2018; 11(3): 144-153. Disponible en: http://scielo.isciii.es/pdf/albacete/v11n3/1699-695X-albacete-11-03-00144.pdf

25. Pamo-Reyna O. Las creencias populares en la medicina moderna. Rev Soc Peru Med Interna [Internet]. 2013;26(1):37-43. Disponible en: http://www.medicinainterna.org.pe/pdf/CONTRIBUCION ESPECIAL 1.pdf

26. Fernández F, Bouza-Vera M, Martínez-Abreu J, Carmenate-Rodríguez Y, Betancourt-González M, García-Nicieza M. El embarazo y la salud bucal. Rev Méd Electrón [Internet]. 2016 Jul-Ago [citado: fecha de acceso]; 38(4). Disponible en: http://www.revmedicaelectronica.sld.cu/index.php/rme/article/ view/1274/3113

27. Alsina LP, Calvo X. La importancia de un buen consejo en salud bucodental durante el embarazo. Matronas profesión. 2014;15(3):73-4.

28. Angarita-Arango AM. Creencias Y prácticas de cuidado genérico de gestantes pertenecientes a la comunidad indígena Wayúu [tesis de maestría]. Bogotá: Universidad Nacional; 2017. 144 p.

29. Ramos-Lafont CP. Prácticas culturales de cuidado de gestantes indígenas que viven en el Resguardo Zenú 
en la Sabana de Córdoba [tesis de maestría]. Bogotá: Universidad Nacional; 2011. 79 p.

30. Machado-Zeledón RJ, Valerio SB. Creencias, mitos y prácticas que tienen las mujeres sobre el embarazo, parto y puerperio en el Centro de Salud Sócrates Flores Vivas, Enero a Marzo 2016 [Tesis Doctoral]. Nicaragua: Universidad Nacional Autónoma de Nicaragua, Managua; 2017. 82 p. Disponible en: https:// repositorio.unan.edu.ni/9828/1/98211.pdf

31. Miranda-Baquedano VM, Trujillo-Serrano DA. Experiencia de los hombres durante el embarazo de su esposa y nacimiento de su hijo(a). Rev Cient Esc Univ Cienc Salud [Internet]. 2015;1(2):17-24. Disponible en: https://www.lamjol.info/index.php/RCEUCS/article/view/2879

32. Pontes-Vieira DR, Figueiredo-de-Oliveira AF, Ferreira-Lopes F, Figuereido-Lopes E, Maia M. Dentists' knowledge of oral health during pregnancy: a review of the last 10 years' publications. Community Dent Health. Jun 2015; 32(2):1-6. Disponible en: https:/www.researchgate.net/publication/281815015_Dentists' knowledge of oral health_during pregnancy_a review of the last 10 years' publications

33. Corchuelo-Ojeda J, Mambuscay JC. Conocimientos de estudiantes de medicina, enfermería y odontología acerca de la salud bucodental en gestantes. Cali, 2015. Rev Saluduninorte. Colombia. 2018; 34 (3): $652-$ 663. Disponible en: http://www.scielo.org.co/pdf/sun/v34n3/2011-7531-sun-34-03-652.pdf 